\title{
Relação dos modelos DuPont com o retorno das ações no mercado brasileiro
}

\section{Relation between DuPont models and stock return in the Brazilian market}

\author{
Eduardo Rosa Soares \\ Mestre em Administração pela FUCAPE Business School \\ E-mail: eduardorsoares@hotmail.com \\ Fernando Caio Galdi \\ Professor Associado da FUCAPE Business School \\ E-mail: fernando.galdi@fucape.br
}

Recebido em 13.10.2010 - Aceito em 17.11.2010 - $4^{a}$. versão aceita em 27.05.201

\section{RESUMO}

Este artigo tem como objetivo comparar os dois modelos de decomposição do ROE, amplamente conhecidos na literatura como modelo DuPont e modelo DuPont modificado, identificando qual dos fatores componentes de cada modelo melhor explica o desempenho das ações de empresas brasileiras negociadas na Bovespa. Diferentemente do modelo DuPont tradicional, o modelo DuPont modificado separa, explicitamente, os resultados operacionais dos resultados financeiros das empresas. Para a avaliação, a análise considera todas as empresas listadas na Bovespa no período de 1995 a 2008. Os resultados encontrados sugerem que o ROA (componente do modelo DuPont tradicional) possui maior poder explicativo, quanto à geração de valor para as ações das empresas do que o ROA operacional (modelo DuPont modificado). Resultados adicionais demonstram que os fatores operacionais explicam melhor o retorno das ações do que os fatores financeiros.

Palavras-chave: ROA. Modelo DuPont. Análise financeira.

\section{ABSTRACT}

This paper investigates the relation between the ratios resulting from the two different possibilities of ROE decomposition (known in literature as DuPont and modified DuPont analysis) and Brazilian firms' stock returns. Differently from traditional DuPont analysis, the modified DuPont analysis explicitly splits operating and financial performance. To put in practice our analysis, we consider Brazilian firms listed from 1995 to 2008. Our results suggest that $R O A$ (derived from traditional DuPont analysis) has higher explanatory power than operational ROA (derived from modified DuPont analysis) regarding stock returns. Further results show that operating components better explain stock returns than financial components.

Keywords: ROA. DuPont model. Financial analysis. 


\section{INTRODUÇÃO}

A competência com a qual uma empresa emprega seus recursos pode ser avaliada por diversas maneiras. Aspectos mercadológicos (crescimento nas vendas, market-share), operacionais (produtividade, eficiência) e relativos a custos ou a recursos humanos (satisfação dos funcionários, clima) são exemplos de itens que podem ser analisados e relacionados aos retornos obtidos pela empresa.

Adicionalmente, a análise financeira é importante ferramenta para a mensuração do desempenho econômico, especialmente quanto às metas e aos propósitos previamente determinados por ela. Para isso, analistas e gestores de finanças utilizam-se dos números encontrados nas demonstrações financeiras para produzir índices, indicadores e previsões que venham a refletir a situação da empresa com relação à lucratividade, eficiência, crescimento e eficácia de suas ações.

Para Oliveira e Matsumoto (2005) a análise das demonstrações contábeis permite mais que conjecturas sobre o desempenho das organizações. Com base em tais demonstrações podem ser calculados diversos índices que procuram traduzir, matematicamente, a situação atual de sustentabilidade e excelência dos resultados da empresa.

Palepu e Healy (2007) argumentam que a análise dos índices de desempenho do passado e do presente de uma empresa fornece a base para a previsão do desempenho futuro. O propósito da análise desses índices é avaliar a eficácia das políticas da firma em diferentes áreas, possibilitando relacionar valores financeiros a fatores subjetivos e implícitos de gestão da empresa com maior nível de detalhe possível.

O modelo DuPont é uma das formas de organizar e analisar os números encontrados nos relatórios financeiros de uma empresa, com vista a observar o seu desempenho.

Em seu trabalho, Liesz (2002) descreve que esse modelo foi desenvolvido por volta de 1918 quando foi dado ao engenheiro Donaldson Brown, que percebeu a relação matemática entre dois indicadores comumente usados: margem de lucro (uma medida de lucratividade) e giro total do ativo total (uma medida de eficiência) e ROA (retorno sobre o Ativo Total) (LIESZ, 2002). O modelo DuPont original foi, assim, escrito.

Mais tarde, nos anos 70, além de apenas rentabilidade e eficiência operacional, o modo como uma empresa financiava suas atividades (seu grau de endividamento ou "alavancagem") tornou-se a terceira área de atenção de gestores financeiros. $\mathrm{O}$ foco muda do ROA para o ROE (Retun on Equity ou Retorno sobre o Patrimônio Líquido) (LIESZ e MARANVILLE, 2008).

Simplificadamente, esse método decompõe a fórmula comumente conhecida do ROE em três componentes básicos: margem de lucro, giro do ativo e o grau de alavancagem da empresa.

Os índices de margem líquida e giro do ativo medem construtos diferentes e, com isso, possuem diferentes propriedades, pois, enquanto o primeiro advém principalmente de características mercadológicas da empresa (posicionamento, marca forte e nichos de mercado, por exemplo), o segundo aponta o grau de eficiência operacional, ou seja, na utilização dos ativos (máquinas, equipamentos etc.) (SOLIMAN, 2004).

Soliman (2008) afirma que:

Além do poder de marca e preço, a margem de lucro mede a habilidade da firma em controlar custos incorridos para gerar vendas e fornece insights à sensibilidade do lucro operacional ante o preço do produto e a estrutura de custos (...) O giro do ativo captura a eficiência da firma em utilizar ativos operacionais para gerar vendas e é, frequentemente, interpretado como me- 
dida de utilização do ativo pelos gestores. (Tradução nossa)

Os diferentes segmentos industriais, portanto, tendem a buscar níveis semelhantes de retornos sobre o Patrimônio Líquido, porém baseados em diferentes combinações de margem líquida e giro do ativo.

Feroz, Kim e Raab (2003) afirmam que a decomposição pelo modelo DuPont facilita o exame do ROE em termos de uma medida de lucratividade, nível de ativos necessários para gerar vendas e financiamento desses ativos.

A análise empírica de Penman, Richardson e Tuna (2007), a respeito do poder explicativo dos fatores operacionais e de alavancagem sobre os retornos esperados das ações das empresas, conclui que o índice operacional está positivamente relacionado aos retornos futuros das ações, enquanto o índice financeiro não apresenta a mesma correlação.

O modelo DuPont, no entanto, apresenta algumas limitações quanto à sua estrutura e capacidade de análise dos índices que o compõem. De maneira alternativa, Palepu e Healy (2007) apresentam um modelo de decomposição e análise que pretende dar nova visão aos fatores componentes do ROE, separandoos em um indicador do ROA operacional e dois indicadores financeiros: spread e alavancagem financeira líquida.

A partir da decomposição do ROE, é possível analisar, separadamente, os índices que o compõem e procurar perceber como os retornos são afetados pelas diferentes combinações de fatores operacionais (margem de lucro, giro do ativo e retorno sobre ativos operacionais) e financeiros (alavancagem, spread e alavancagem financeira líquida) da empresa, bem como explicar o grau com que cada um desses fatores influencia tais retornos.

Vale ressaltar a importância da análise financeira como ferramenta não apenas para a empresa e seus gestores, mas também para os investidores. Para os primeiros, além de dar condições de desenvolver previsões futuras, também é um dos fundamentos do plane- jamento de políticas, estratégias e objetivos. O benefício para o investidor está em poder, semelhantemente, previsionar desempenhos futuros e auxiliar quanto à tomada de decisões de investimento.

Nesse sentido, os modelos DuPont e alternativo contribuem para a mensuração de retornos de empresas e setores, fornecendo indicadores que suportam análises, previsões e tomadas de decisão dos agentes do mercado de capitais.

Para fins de simplificação e maior clareza dos conceitos, definir-se-á a nomenclatura "modelo DuPont" e "modelo alternativo" para a decomposição do ROE nessas fórmulas no decorrer desta pesquisa.

Tomando o exposto acima, o artigo propõe o seguinte problema: Sob a ótica dos modelos de análise de demonstrações financeiras apresentados, qual das duas formas de retorno sobre os ativos (ROA e ROA operacional) se relaciona em maior grau com o retorno das ações das brasileiras listadas na Bovespa?

Adicionalmente, esta pesquisa procura investigar, também, se fatores operacionais estão mais relacionados aos retornos das ações que os fatores financeiros, bem como se há relação entre os fatores de alavancagem das empresas e o retorno de suas ações.

A partir daí são formuladas as seguintes hipóteses de pesquisa:

$\mathrm{H}_{0} 1$ - Não existe diferença quanto ao poder explicativo dos indicadores ROA operacional e ROA quanto ao desempenho das ações das empresas brasileiras listadas na Bovespa.

$\mathrm{H}_{0} 2$ - Dados ambos os modelos, não existe diferença entre o poder explicativo dos índices operacionais e financeiros quanto ao desempenho das ações das empresas brasileiras listadas na Bovespa.

$\mathrm{H}_{0} 3$ - Não há relação entre o grau de alavancagem das empresas brasileiras listadas na Bovespa e o retorno de suas ações, e ela é negativa, corroborando com as conclusões de Penman, Richardson e Tuna (2007). 
A principal justificativa para o desenvolvimento do trabalho reside no fato de poder elucidar a respeito da importância da consideração dos retornos sobre o ativo na análise de desempenho de empresas no mercado de capitais, podendo, ainda, esclarecer qual dos dois modelos melhor se aplica à realidade dos agentes de mercado em termo de utilidade prática.

Procura, também, testar se os resultados obtidos pela aplicação dos modelos DuPont no mercado brasileiro corroboram com aqueles de Penman, Richardson e Tuna (2007), obtidos no mercado norte-americano, a fim de verificar se as especificidades de ambos mercados podem ser determinantes para a análise.

O presente trabalho contribui com a literatura nacional de contabilidade e finanças, pois apresenta evidências de como em métricas tradicionais de análise da rentabilidade das empresas (fórmulas "DuPont"), tratadas em livros-texto extensamente utilizados, o retorno sobre os ativos (ROA) e o retorno sobre os ativos operacionais (ROA oper.) se relacionam com o retorno de mercado (geração de valor) das empresas brasileiras. Adicionalmente, a análise implementada levanta evidências para uma longa discussão de qual seria a métrica mais adequada para a mensuração da rentabilidade da empresa, ao comparar o desempenho da análise tradicional do ROE (fórmula "DuPont") com a análise modificada do ROE (Fórmula "DuPont" modificada).

\section{REFERENCIAL TEÓRICO}

\subsection{Análise fundamentalista}

A análise fundamentalista engloba a utilização de informação contida nos relatórios e nas demonstrações financeiras atuais e passadas, em conjunto com dados macro e microeconômicos, estratégicos e financeiros, para buscar o valor intrínseco da empresa, ou seja, ela estuda a variação de fatores que afetam o equilíbrio entre a oferta e a demanda do mer-
Os resultados apontam que o ROA possui maior poder explicativo, quanto à geração de valor para as ações das empresas do que o ROA operacional, em função de sua maior relação quanto ao desempenho delas. Uma explicação para esse resultado reside no fato de que ao incluir o resultado financeiro, considerando-se as altas taxas de juros no mercado brasileiro, o ROA representa, mais adequadamente, a geração de valor econômico da empresa do que o ROA operacional, que considera estritamente as atividades operacionais da empresa.

$\mathrm{O}$ artigo está organizado da seguinte maneira: a seção 2 contextualiza o leitor acerca do tema e seus conceitos básicos, bem como apresenta problemas de pesquisa, objetivos, hipóteses e justificativa para sua realização. Na seção 3, apresenta-se o arcabouço teórico, que servirá de base para a definição de conceitos e desenvolvimento das ideias relativas ao tema. Logo após, é descrita a metodologia usada para os testes empíricos, em que são apresentadas as variáveis e os modelos de regressão construídos, as fontes e critérios de coleta de dados e os resultados esperados. $\mathrm{Na}$ quarta parte do trabalho é feita a análise dos resultados dos testes empíricos, destacando os principais pontos observados diante dos objetivos aqui propostos. Por fim, extraem-se as conclusões do trabalho, apresentadas com base nos resultados obtidos e em confronto com a teoria abordada, e apresentam-se sugestões para trabalhos futuros.

cado. A diferença entre o valor intrínseco da ação e o seu valor de mercado seria, dessa forma, um indicador do retorno extraordinário oriundo do investimento naquele título (ROSTAGNO; SOARES; SOARES, 2008).

Dessa maneira, esse tipo de análise se preocupa, portanto, em traduzir o impacto da informação disponível a respeito da empresa na estimativa de como deverá ser o desem- 
penho futuro do negócio. Assim, é, também, fundamental para se ter um conhecimento abrangente sobre a empresa, influenciando no processo decisório tanto interno quanto externo (GALDI et al.2009).

A análise fundamentalista preocupa-se em extrair dos dados disponíveis o máximo que possa ser transformado em informações concernentes ao desempenho futuro das empresas, a fim de desenvolver análises e previsões sobre oferta, demanda e preço das ações (GALDI et al. 2009).

Diversos autores (FAMA, 1970; FAMA; FRENCH, 1992; LEV; THIAGARAJAN, 1993; ABARBANEL; BUSHEE, 1997, 1998; PENMAN e ZHANG, 2002, dentre outros) se utilizam da teoria fundamentalista no desenvolvimento de novas teorias que se baseiam em informações de mercado e apontam relações entre essas e variáveis de desempenho (como lucros, retornos e alavancagem), comportamento de agentes de mercado (reação de investidores e analistas quanto a mudanças) e o poder explicativo contido nas informações.

Chen e Zhang (2006), por exemplo, afirmam que se os dados contábeis possuem caráter informativo acerca de valores relativos aos fundamentos das empresas e de mudanças nesses valores, então eles devem estar correlacionados com variações nos preços das ações dessas empresas.

Nesse sentido, reconhece-se a importância do papel da análise fundamentalista como instrumento de quebra de assimetria de informação entre o administrador e os demais agentes do mercado, que objetiva determinar e predizer a efetiva realidade econômica futura do negócio (GALDI et al. 2009). Com isso a qualidade das informações fornecidas tem papel determinante no funcionamento do mercado de capitais, haja vista que, quanto maior ela for, mais acurados serão os relatórios e as previsões fornecidos por analistas, maior será a confiança de investidores no mercado e mais bem embasadas serão suas decisões. Em suma, quanto maior a quali- dade da informação, menor será a assimetria entre os agentes de mercado e, consequentemente, menor será o risco de seleção adversa (GALDI et al. 2009).

Presente na literatura há anos e ainda tomado como base de diversas teorias em Finanças, a Hipótese de Mercado Eficiente (FAMA, 1970) conjectura que um mercado é eficiente na forma forte quando os preços dos títulos que o compõem refletem, integralmente, todas as informações disponíveis naquele momento (públicas ou privadas, em qualquer tempo considerado). A aceitação integral da hipótese da eficiência de mercado na forma forte torna as informações públicas irrelevantes para a seleção de investimentos. Contudo, a literatura de Finanças e Contabilidade tem mostrado que a premissa de que o mercado é eficiente na forma forte não é observada na prática, surgindo a ampla aceitação dos conceitos de que o mercado seja eficiente na forma semiforte ou na forma fraca. Nessas situações, a informação pública (na qual o modelo DuPont se baseia) pode ser relevante para a seleção de investimentos.

Baseado no exposto até aqui os modelos DuPont e DuPont alternativo pretendem ser úteis à análise fundamentalista, na medida que traduzem dados contábeis em informações a respeito do desempenho passado da empresa nos níveis operacional e financeiro. A partir daí pode-se investigar se os índices que compõem esses modelos, em ambos os níveis, possuem relação com os retornos das ações das empresas brasileiras citadas na Bovespa.

A seguir, são detalhados os modelos DuPont e alternativo de cálculo do retorno sobre o patrimônio líquido (ROE).

\subsection{O modelo DuPont}

O modelo DuPont é uma maneira de decompor o ROE em três fatores que, analisados individualmente, representam a margem líquida, o giro dos ativos e a alavancagem da empresa. O modelo DuPont pode ser expresso como: 


$$
R O E_{t}=\frac{L L_{t}}{P L_{t-1}}
$$

$R O E_{t}=R O A \times A L$

$R O E_{t}=$ margem líquida $_{\mathrm{t}} \times$ giro do ativo $_{\mathrm{t}} \times$ alavancagem ${ }_{t}$

$$
=\frac{L L_{t}}{\text { Vendas }_{t}} \times \frac{\text { Vendas }_{t}}{A T_{t-1}} \times \frac{A T_{t-1}}{P L_{t-1}}
$$

em que:

$\mathrm{ROE}_{\mathrm{t}}$ : retorno sobre o patrimônio líquido no ano t;

ROA: o retorno sobre o ativo no ano t;

$\mathrm{LL}_{\mathrm{t}}$ : lucro líquido no ano $\mathrm{t}$;

Vendas: receita bruta total apurada no ano $t$; $\mathrm{AT}_{\mathrm{t}-1}$ : ativo total no ano $\mathrm{t}-1$;

$\mathrm{PL}_{\mathrm{t}-1}$ : patrimônio líquido no ano $\mathrm{t}-1$;

ML: margem líquida;

GA: giro do ativo;

AL: alavancagem.

O retorno sobre os ativos (ROA) reflete o lucro gerado pela empresa com relação ao emprego de seus ativos para tal. Essa medida, entretanto, não faz distinção da proporção de lucro que foi gerado pela rentabilidade das suas vendas e pela eficiência com que utilizou seus ativos para produzir. A decomposição do ROA em margem líquida, uma medida de rentabilidade, e giro do ativo, uma medida de eficiência, serve para melhor descrever os resultados encontrados.

$\mathrm{O}$ fator margem líquida (a divisão do lucro líquido pela receita bruta) demonstra quanto a empresa obteve de lucro sobre as vendas realizadas no período. Considerando que o lucro é a diferença entre receitas e despesas, pode-se dizer que empresas com alto grau de margem líquida são, em geral, portanto, aquelas que conseguem administrar a relação entre sua estrutura de custos (menores despesas) e seu esforço de marketing (maior receita), de forma que seus preços possibilitem manter grande a distância entre receitas e despesas. Quanto maior a margem líquida, mais lucro a empresa gera por venda realizada.
Uma empresa pode, também, mensurar o grau de eficiência com que utiliza seu ativo, ou seja, dividindo-se a receita bruta por seu ativo consegue-se perceber quanto os bens e direitos da empresa geram de receita para ela. Mais eficiente é a empresa que mais receita gera utilizando-se de menos ativos quanto for possível e maior é seu giro dos deles.

Os índices de margem líquida e de giro do ativo medem construtos diferentes e, dessa maneira, possuem diferentes propriedades, pois, enquanto o primeiro advém principalmente de características mercadológicas da empresa (posicionamento, marca forte e nichos de mercado, por exemplo), o segundo aponta o grau de eficiência operacional, ou seja, na utilização dos ativos (máquinas, equipamentos etc.) (SOLIMAN, 2004).

A alavancagem evidencia a medida com que o ativo total da empresa é financiado por capital próprio, dividindo-se o primeiro pelo patrimônio líquido. Quanto maior for essa relação, portanto, menor é a participação do capital próprio da empresa no financiamento dos ativos.

Alguns teóricos argumentam que o modelo DuPont tradicional apresenta algumas limitações quanto à sua estrutura e capacidade de análise dos índices que o compõem. Os ativos incluem tanto ativos operacionais quanto ativos financeiros. $\mathrm{O}$ lucro líquido inclui ganhos advindos de atividades operacionais, bem como receitas e despesas com juros, que são consequências de decisões financeiras. Assim, ao considerar o ROA (margem líquida $\mathrm{x}$ giro do ativo), a análise mistura o resultado operacional com o resultado financeiro da empresa. Ainda, o índice de alavancagem utilizado não reconhece o fato de que o Caixa e os Investimentos de Curto Prazo de uma empresa são "débitos negativos" em sua essência, visto que podem ser usados para reduzir a dívida bruta na empresa no balanço (PALEPU; HEALY, 2007). 


\subsection{O modelo alternativo (DuPont modificado)}

Considerando as limitações do modelo DuPont apresentadas acima, Palepu e Healy (2007) apresentam o seguinte modelo alternativo de decomposição e análise do ROE de maneira a isolar os resultados operacionais e financeiros dos componentes do modelo $\mathrm{Du}$ Pont:

$$
\begin{aligned}
& R O E_{t}=R O A o p+\text { Spread } \times A F L \\
& \text { em que: }
\end{aligned}
$$

ROAop: retorno sobre ativos operacionais líquidos;

Spread: efeito econômico incremental decorrente da introdução de dívida na estrutura operacional. É calculado como ROAop - Taxa de juros efetiva após imp.;

AFL: alavancagem financeira líquida.

Especificamente, têm-se:

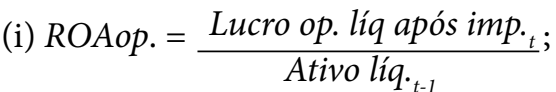

(ii) Taxa de juros efetiva após imp. =

$$
\frac{\text { Desp. líq. com juros após imp. } ._{t}}{\text { Dívida líq. }}
$$

(iii) Alavancagem finaceira líquida $=$

$$
\frac{\text { Dívida líq. }}{P L_{t-1}}
$$

O Quadro 1, abaixo, apresenta a definição das principais variáveis utilizadas nesse estudo:

Quadro 1 Conceitos do modelo alternativo de decomposição do ROE

\begin{tabular}{|l|l|}
\hline Conceitos & Significado em Dados Contábeis \\
\hline Despesa líquida com juros após impostos & (despesas financeiras - receitas financeiras)x(1-IR) \\
\hline Lucro operacional líquido após impostos & Lucro líquido + Despesa líquida com juros após impostos \\
\hline Operating working capital & (AC - disponível e investimentos CP) - PC \\
\hline Ativo líquido de longo prazo & $\begin{array}{l}\text { Ativo não circulante - [Exigível LP - (financiamentos LP + Debêntures LP) } \\
\text { + Participação acionistas Minoritários] }\end{array}$ \\
\hline Dívida líquida & (Financiamentos LP + Debêntures LP) - disponível e investimentos CP \\
\hline Ativo Líquido & Operating working capital + Ativo líquido LP \\
\hline
\end{tabular}

O ROA operacional captura a lucratividade operacional sem conter os efeitos da alavancagem financeira da equação anterior (SOLIMAN, 2008), sendo uma medida do grau de lucratividade com que uma empresa gera lucros operacionais a partir do emprego de seus ativos operacionais (PALEPU, HEALY 2007).

Feroz, Kim e Raab (2003) afirmam que a decomposição pelo modelo DuPont facilita o exame do ROE em termos de uma medida de lucratividade, nível de ativos necessários para gerar vendas e financiamento desses ativos. Desta maneira é possível ainda observar o grau de alavancagem da empresa e, consequentemente, analisar como esses três fatores se inter-relacionam na composição dos resultados da empresa.
O efeito econômico resultante da tomada de dívida pela empresa (o spread) é positivo enquanto o retorno sobre os ativos operacionais for maior que o custo da dívida (PALEPU e HEALY, 2007). Com isso, uma empresa reduz seu retorno sobre o patrimônio líquido (ROE) se não é capaz de gerar retornos operacionais que lhe permitam arcar com custos relativos a juros.

O grau de dívida líquida em relação ao capital próprio que a empresa possui (alavancagem financeira líquida) incrementa o efeito positivo ou negativo do spread, sendo que a multiplicação desses dois fatores apresenta o ganho dos acionistas com a alavancagem financeira (PALEPU; HEALY 2007). 


\subsection{Trabalhos anteriores}

Soliman $(2004 ; 2008)$ apresenta duas contribuições para o estudo na área. Inicialmente, o autor investiga o uso da análise DuPont ajustada à indústria específica para prever lucratividade futura e estabelecer comparações (SOLIMAN, 2004). O autor pretendeu verificar se é útil contextualizar a empresa dentro de seu ambiente competitivo de produção quando compara seus resultados. No estudo citado, investiga-se se o uso do modelo DuPont ajustado às indústrias específicas (média de cada indústria) é uma ferramenta útil para prever mudanças no ROA das empresas, em contrapartida ao uso do modelo sem esse ajuste, em que se usa a média dos retornos de todo o mercado como base de comparação de desempenho. $\mathrm{O}$ autor, ainda, afirma que as forças competitivas devem conferir diferentes olhares sobre valores de margem líquida e giro do ativo, ante as diferenças com relação à essência de ambas as medidas, no que tange ao que refletem sobre o desempenho da empresa. Especificamente Soliman (2004) relata:

Há razões para se esperar que as forças competitivas afetem estas duas fontes de lucratividade de formas diferentes. Altas margens de lucro frequentemente atraem novos entrantes ao mercado ou imitações rápidas de novas idéias por rivais. A competição resultante causa a reversão das altas margens de lucro para níveis normais, sugerindo benefícios mais transitórios. Por outro lado a competição pode ser menos ameaçadora à utilização eficiente de ativos. É mais difícil imitar processos produtivos mais eficientes de outra firma, pois tal imitação frequentemente envolve grandes e custosas barreiras relacionadas a fábricas e operações atuais.

Os diferentes segmentos industriais, portanto, tendem a buscar níveis semelhantes de retornos sobre o Patrimônio Líquido, porém baseados em diferentes combinações de margem líquida e giro do ativo.
Finalmente, Soliman (2004) conclui que a simples decomposição do modelo DuPont, aliado a um ajuste à indústria, resulta em aumento na habilidade de previsão de mudanças futuras no ROA e a lucratividade anormal derivada de margens de lucros anormais é menos persistente que se derivada de giros do ativo anormais. Adicionalmente, observase que se as variações nos índices financeiros são mais bem explicadas pelo setor produtivo do qual faz parte uma empresa que por fatores econômicos em geral, então o ajuste à indústria pode ajudar a extrair informações das varáveis contábeis e aumentar o seu poder de previsão.

Em outro trabalho, Soliman (2008) examina a utilidade do modelo DuPont, verificando se o uso das informações contidas em sua estrutura pelos agentes do mercado estão associadas aos seus retornos do mesmo e às previsões e reações de analistas e investidores. No desenvolvimento da pesquisa, ele utiliza, também, o modelo alternativo para avaliar e confirmar o poder explicativo da margem líquida e do giro do ativo sobre oscilações no ROA operacional.

O mesmo autor percebe que o poder explicativo do $\triangle A T O$ (a variação do giro do ativo em um período) é, estatisticamente, significante e possui correlação positiva com a noção de que o giro do ativo traz novas informações sobre mudanças futuras na lucratividade (SOLIMAN, 2008), ressaltando, ainda, que o mercado reconhece as implicações futuras dos componentes do modelo DuPont sobre o ROA operacional.

Modigliani e Miller (1958) desenvolvem uma teoria a respeito dos efeitos da estrutura de capital na avaliação de empresas (empresas, individualmente, e indústrias) e no retorno das ações, e como esses efeitos podem ser inferidos a partir de dados objetivos de mercado, avaliando, também, as implicações da teoria sobre o custo de capital das empresas.

Para o presente trabalho, mostram-se interessantes duas proposições da teoria de 
Modigliani e Miller (1958): I) a empresa não é capaz de mudar o seu valor total (no caso representado pelo valor de seus títulos), simplesmente por meio da alteração das proporções na estrutura de capital, o que representa dizer que a política de financiamento é irrelevante para seus retornos; II) a introdução de dívida (capital de terceiros), na estrutura de capital da empresa, gera aumento nos retornos esperados, ou seja, a alavancagem é positivamente correlacionada com o retorno das ações das empresas.

Fama e French (1992) buscaram avaliar, por meio de dados em cross-section, o papel do risco $(\beta)$ de mercado, do tamanho da firma, da alavancagem, do índice $\mathrm{E} / \mathrm{P}$ (earningsprice, ou relação ganhos-preço da ação), e do índice book-to-market (relação entre o valor contábil da empresa e seu valor de mercado) com a média dos retornos das ações das empresas. Os resultados obtidos foram significativos, sendo os principais: $o \beta$, aparentemente, não explica o retorno médio das ações; por outro lado, há relação entre os retornos e as outras variáveis; a combinação das variáveis tamanho da firma e book-to-market consegue absorver o papel da alavancagem e do índice $\mathrm{E} / \mathrm{P}$ nos retornos das ações. O principal resultado, no entanto, aponta para o fato de que duas variáveis, facilmente mensuradas, o tamanho da empresa e seu book-to-market conseguem capturar a variação na média dos retornos das ações associados a tamanho: E/P, book-to-market e alavancagem (FAMA; FRENCH, 1992).

Penman, Richardson e Tuna (2007) fundamentaram sua pesquisa nos resultados de Fama e French (1992). Partindo da premissa de que o índice $\mathrm{B} / \mathrm{P}$ (book-to-price, o mesmo que bookto-market) correlaciona-se positivamente com o retorno médio das ações e que ele "absorve" o papel da alavancagem nos retornos, os primeiros autores decompõem esse índice em dois: o fator enterprise book-to-market (relativo a operações, e que assim reflete riscos operacionais) e o componente de alavancagem (que reflete riscos financeiros). E, a partir daí, desenvolvem uma análise empírica acerca do poder explicativo dos fatores operacionais e financeiros contidos no índice $\mathrm{B} / \mathrm{P}$ sobre os retornos esperados das ações das empresas.

Penman, Richardson e Tuna (2007) destacam que:

Uma noção elementar em finanças corporativas é a de que o risco do capital próprio (e os retornos esperados sobre o capital próprio) é determinado pelo risco operacional inerente às operações da firma (também chamado risco da firma, risco da empresa, risco do negócio, ou risco do ativo) e pelo risco financeiro que advém de tomada de dívida, que alavanca o investimento do capital próprio nas operações (...) Dado o risco operacional, os retornos médios aumentam com a alavancagem (...) A noção de que tomar dívida aumenta o risco e retornos esperados se tornou largamente aceita, tanto que qualquer observação contrária é considerada anormal.

Os resultados da análise empírica mostram que o índice operacional está positivamente relacionado aos retornos futuros das ações. Contudo, diferentemente do que se esperava, o índice de alavancagem financeira, uma vez condicionado ao índice bookto-price, apresenta correlação negativa com os retornos, tanto para empresas com alto $\mathrm{B} / \mathrm{P}$ quanto para aquelas com baixo B/P. As conclusões de Penman, Richardson e Tuna (2007) fundamentaram-se na aplicação e desenvolvimento da seguinte equação:

$R_{t-1}=\alpha_{0}+\lambda_{1}+\frac{N O A_{t}}{P_{t} N O A}+\lambda_{2} \frac{N D_{t}}{P_{t}}+\ldots+\varepsilon_{t}$ em que:

$\mathrm{R}_{\mathrm{t}+1}:$ média do retorno das ações no ano $\mathrm{t}+1$; $\mathrm{NOA}_{t}$ : ativos não operacionais (non-operating assets) no ano t;

$\mathrm{ND}_{\mathrm{t}}$ : dívida líquida (net debt) no ano $\mathrm{t}$;

$\mathrm{P}_{\mathrm{t}} \mathrm{NOA}$ : valor de mercado (market value) dos ativos operacionais líquidos em $t$;

$\mathrm{P}_{\mathrm{t}}$ : valor de mercado (market value) da empresa no ano t; 
A conclusão de Penman, Richardson e Tuna (2007) é de que o efeito B/P (de correlação positiva entre $\mathrm{B} / \mathrm{P}$ e retornos esperados) não absorve o incremento da alavancagem. Mais do que isso, esse incremento resulta em menores retornos.

Dentre os trabalhos elaborados no Brasil, Oliveira e Matsumoto (2005) seguem a linha de Soliman (2008), ao analisarem o desempenho do setor de siderurgia e metalurgia do Brasil, à luz do modelo DuPont, entre 1999 e 2003.

\section{METODOLOGIA}

\subsection{Seleção e coleta de dados}

Para a condução da pesquisa foram selecionadas as empresas com ações negociadas na BOVESPA, no período entre 1995 e 2008, tendo sido consideradas, apenas, as ações de maior liquidez de cada empresa e excluíndose as empresas financeiras (bancos e seguradoras). Os dados foram coletados da base de dados do software Economatica.

Optou-se pela coleta de dados a partir de 1995, a fim de evitar possíveis problemas oriundos dos efeitos inflacionários que vigoraram antes do Plano Real (junho de 1994).

Para que se pudesse chegar aos valores finais dos índices a serem testados empiricamente, foram selecionados e organizados, a partir das demonstrações financeiras das empresas, os seguintes dados contábeis: Lucro Líquido, Receita Bruta, Ativo Total, Exigível em Longo Prazo, Realizável em Longo Prazo, Financiamentos de Longo Prazo, Debêntures de Longo Prazo, Outros Ativos de Longo Prazo, Despesas Financeiras, Receitas Financeiras, Disponível e Investimentos de Curto Prazo, Financiamento de Curto Prazo, Debêntures de Curto Prazo, Ativo Circulante, Passivo Circulante, Passivo Não Circulante e Participações de Acionistas Minoritários.

Os dados utilizados compreendem o período entre 31 de Dezembro do ano anterior e 31 de Dezembro do ano observado e são relativos às demonstrações consolidadas das empresas. Após a coleta de dados na Econo-
Corroborando com as pesquisas de Soliman (2008), Oliveira e Matsumoto (2005) apuraram dados semelhantes quanto à ROA, margem líquida e giro do ativo, o que permitiu extrair conclusões quanto ao desempenho das empresas de forma contextualizada, revelando que a margem líquida tem grande influência no ROA das empresas e é com o aumento dela que se fundamenta, principalmente, o poder de retorno do setor. matica, esses dados contábeis foram transformados nos indicadores financeiros de margem líquida, giro do ativo, ROA, alavancagem, ROA operacional, Spread, alavancagem financeira líquida e retorno das ações.

No conjunto dos dados selecionados foram, também, construídas variáveis de controle, de modo a permitir uma melhor especificação do modelo, minimizando a probabilidade de omissão de variáveis que possam estar correlacionadas simultaneamente com as variáveis explicativas e que, portanto, possam levar a inferências ou conclusões erradas a respeito dos resultados encontrados (FIGUEIREDO, FAMÁ, SILVEIRA, 2005). Pretende-se, dessa maneira, dar melhor qualidade estatística ao modelo.

Foram aplicadas, nesta pesquisa, as seguintes variáveis de controle:

Book-to-market (BM): trata-se da relação entre o valor contábil de uma empresa, dado por seu Patrimônio Líquido, e o seu valor de mercado em um determinado ano t. $\mathrm{O}$ valor de mercado é obtido pela multiplicação do preço da ação no final do ano multiplicado pelo número de ações da empresa no mesmo período.

Beta: medida da volatilidade de uma ação em relação à volatilidade do mercado.

Tamanho: medido pelo logarítimo natural do Ativo Total da empresa ao final do ano $t$.

PIB: representado pelo logarítimo natural 
do Produto Interno Bruto do Brasil no ano t.

Taxa de juros: média da taxa Selic praticada no ano t.

Câmbio: média da taxa PTAX de compra no ano $t \mathrm{em} \mathrm{R} \$ / \mathrm{US} \$$.

Inflação: índice IPCA (Índice de Preços ao Consumidor Amplo) de inflação no ano t.

Os dados relativos às informações contábeis e de mercado das empresas foram coletados no software Economatica, obedecendo aos demais critérios utilizados para as variáveis dependentes e independentes.

Os valores de PIB e Inflação foram colhidos na base de dados do Instituto Brasileiro de Geografia e Estatística (IBGE) ${ }^{1}$, ao passo que as taxas de câmbio e de juros foram extraídas da base de dados do Banco Central do Brasil ${ }^{2}$.

\subsection{Modelos empíricos}

Na definição das variáveis a serem estudadas, o retorno das ações de cada empresa foi definido como a oscilação, ou seja, a variação no preço de fechamento da ação da empresa durante o ano observado, obedecendo à seguinte relação:

$R_{i t}=\frac{P_{i, t}-P_{i, t-1}}{P_{i, t-1}}$

em que:

R: retorno da ação da empresa $i$ no ano t;

P: preço da ação da empresa $i$.

Já o retorno sobre o Patrimônio Líquido (ROE) teve sua forma original decomposta em duas formas diferentes (PALEPU e HEALY, 2007):

a) $R O E_{t}=R O A \times A L$

$=M L \times G A \times A L$

$=\frac{L L_{t}}{\text { Vendas }_{t}} \times \frac{\text { Vendas }_{t}}{A T_{t-1}} \times \frac{A T_{t-1}}{P L_{t-1}}$

em que:

$\mathrm{ROE}_{\mathrm{t}}$ : retorno sobre o patrimônio líquido no ano t;

$\mathrm{ROA}_{\mathrm{t}}$ : o retorno sobre o ativo no ano t;

$\mathrm{LL}_{\mathrm{t}}$ : lucro líquido no ano $\mathrm{t}$;
Vendas: receita bruta total apurada no ano t;

$\mathrm{AT}_{\mathrm{t}-1}$ : ativo total no ano $\mathrm{t}-1$;

$\mathrm{PL}_{\mathrm{t}-1}$ : patrimônio líquido no ano $\mathrm{t}-1$;

ML: margem líquida;

GA: giro do ativo;

AL: alavancagem.

b) $R O E=R O A o p+$ Spread $\times A F L$

em que:

ROAop: retorno sobre ativos operacionais líquidos;

Spread: efeito econômico incremental decorrente da introdução de dívida na estrutura operacional;

AFL: alavancagem financeira líquida.

No intuito de verificar as hipóteses propostas para a pesquisa, foram formulados os seguintes modelos estatísticos:

$$
\text { I) } \begin{aligned}
R_{i, t}= & \alpha_{0}+\beta_{1} R O A_{i, t}+\beta_{2} A L_{i, t}+\beta B M_{i, t}+\beta \text { beta }_{i, t} \\
& +\beta \operatorname{tam}_{i, t}+\beta P I B_{t}+\beta \text { Selic }_{t}+\beta \text { Câmbio }_{t} \\
& +\beta \operatorname{Inf}_{t}+\varepsilon
\end{aligned}
$$

em que:

$\mathrm{R}_{\mathrm{i}, \mathrm{t}}$ : retorno da ação da empresa $i$ no ano t; $\mathrm{ROA}_{\mathrm{t}}$ : o retorno sobre o ativo no ano $t$;

$\mathrm{AL}_{\mathrm{i}, \mathrm{t}}$ : alavancagem da empresa $i$ no ano $t$;

$\mathrm{BM}_{\mathrm{i}, \mathrm{t}}$ : a relação book-to-market da empresa $i$ no ano t;

beta $_{\mathrm{i}, \mathrm{t}}$ o beta da empresa $i$ no ano $t ;$

$\operatorname{tam}_{\mathrm{i}, \mathrm{t}}:$ o logarítimo natural do ativo total da empresa $i$ no ano t;

PIB $t_{t}$ o logarítimo natural do PIB do Brasil no ano t;

Selic: a média da taxa de juros Selic no ano t; Câmbiót a taxa média de câmbio no Brasil no ano t;

Inflação: a inflação acumulada no ano t.
II) $R_{i, t}=\alpha_{0}+\beta_{1} M L_{i, t}+\beta_{2} G A_{i, t}+\beta_{3} A L_{i, t}$ $+\beta B M_{i, t}+\beta$ beta $_{i, t}+\beta$ tam $_{i, t}$ $+\beta$ PIB $_{t}+\beta$ Selic $_{t}+\beta$ Câmbio $_{t}$ $+\beta \operatorname{Inf} f_{t}+\varepsilon$


em que:

$\mathrm{R}_{\mathrm{i}, \mathrm{t}}$ : retorno da ação da empresa $i$ no ano $\mathrm{t}$;

$\mathrm{ML}_{\mathrm{i}, \mathrm{t}}$ : margem líquida da empresa $i$ no ano t; $\mathrm{GA}_{\mathrm{i}, \mathrm{t}}$ : giro do ativo da empresa $i$ no ano t; $\mathrm{AL}_{\mathrm{i}, \mathrm{t}}$ : alavancagem da empresa $i$ no ano t; $\mathrm{BM}_{\mathrm{i}, \mathrm{t}}$ : a relação book-to-market da empresa $i$ no ano t;

beta $_{\mathrm{i}, \mathrm{t}}$ o o beta da empresa $i$ no ano t;

$\operatorname{tam}_{\mathrm{i}, \mathrm{t}}:$ o logarítimo natural do ativo total da empresa $i$ no ano t;

$\mathrm{PIB}_{\mathrm{t}}$ : o logarítimo natural do PIB do Brasil no ano t;

Selic: a média da taxa de juros Selic no ano t; Câmbio: : a taxa média de câmbio no Brasil no ano t;

Inflação: a inflação acumulada no ano t.

III) $R_{i, t}=\alpha_{0}+\beta_{1}$ ROAop $_{i, t}+\beta_{2}$ Spread $_{i, t}+\beta_{3} A F L_{i, t}$ $+\beta B M_{i, t}+\beta$ beta $_{i, t}+\beta$ tam $_{i, t}+\beta P I B_{t}$ $+\beta$ Selic $_{t}+\beta$ Câmbio $_{t}+\beta \operatorname{Inf}_{t}+\varepsilon$

em que:

$\mathrm{R}_{\mathrm{i}, \mathrm{t}}$ : retorno da ação da empresa $i$ no ano t; ROAop $_{\mathrm{i}, \mathrm{t}}$ : retorno sobre ativos operacionais líquidos da empresa $i$ no ano $t$;

Spread $_{\mathrm{i}, \mathrm{t}}$ : efeito econômico incremental decorrente da introdução de dívida na estrutura operacional da empresa $i$ no ano t;

$\mathrm{AFL}_{\mathrm{i}, \mathrm{t}}$ : alavancagem financeira líquida $\mathrm{da} \mathrm{em}$ presa $i$ no ano t;

$\mathrm{BM}_{\mathrm{i}, \mathrm{t}}$ : a relação book-to-market da empresa $i$ no ano t;

beta $_{\mathrm{i}, \mathrm{t}}:$ o beta da empresa $i$ no ano t;

$\operatorname{tam}_{\mathrm{i}, \mathrm{t}}:$ o logarítimo natural do ativo total da empresa $i$ no ano t;

$\mathrm{PIB}_{\mathrm{t}}$ : o logarítimo natural do PIB do Brasil no ano t;

Selic: a média da taxa de juros Selic no ano t; Câmbio: : a taxa média de câmbio no Brasil no ano t;

Inflação: a inflação acumulada no ano t.

Note-se que do método DuPont são formulados dois modelos de regressão. O modelo I permite analisar os resultados da variável ROA (ML x GA) em face da variável ROAop do modelo III, comparando, assim, os componentes operacionais de cada equação, a fim de verificar qual das duas variáveis gera mais valor para as empresas brasileiras listadas na Bovespa, objetivo principal desta pesquisa.

Por meio dos modelos I, II e III pretendese, também, estabelecer análises comparativas capazes de averiguar a relação entre as variáveis, dentro de cada modelo, com os retornos. Em outras palavras, objetivam investigar se o comportamento dos retornos das ações de cada empresa está significativamente relacionado aos resultados operacionais (ML, GA, ROA e ROAop) e/ou financeiros (AL, Spread e AFL), como se relacionam e em que grau.

O modelo II aprofunda a análise do modelo I, transformando a variável operacional ROA em duas, dando melhor noção de como se fundamenta o retorno sobre os ativos, ou seja, como a empresa combina rentabilidade (ML) com eficiência operacional (GA).

\subsection{Análise e tratamento dos dados}

A metodologia utilizada nesta pesquisa compreende testes em dados transversais (cross-section) e em pooled regression. Com os dados em cross-section, desenvolveram-se testes de cada modelo empírico (I e II), ano por ano, tomando-se todas as empresas listadas com dados disponíveis para as análises implementadas no período de 1995 a 2008. No tratamento dos dados, a fim de minimizar o efeito de valores extremos sobre as amostras, ou seja, aqueles valores cujas eliminações produzem mudanças significativas na regressão (WOOLDRIDGE, 2006), foram excluídos os $2,5 \%$ dos maiores e menores valores de cada fator das equações. Pretende-se, assim, tornar a amostra mais homogênea e menos influenciada por valores extremos. Para isso foi utilizada a técnica estatística trimmed com a exclusão de outliers. Por esse método, a média de um conjunto finito de $\mathrm{N}$ números é obtida colocando o conjunto em ordem crescente, removendo o percentual de extremos preestabelecidos e computando a média dos valores restantes. Uma vez rodados os testes, chegou-se a uma média de 206 empresas por teste. A distribuição dos dados, com base na sua data, é apresentada na Tabela 1. 
Tabela 1 Número de observações por variável por ano

\begin{tabular}{c|c|c|c|c|c|c|c|c}
\hline Ano & Retorno & ML & GA & ROA & AL & ROAop & Spread & AFL \\
\hline 1995 & 261 & 218 & 212 & 208 & 243 & 208 & 207 & 242 \\
\hline 1996 & 268 & 203 & 196 & 194 & 257 & 224 & 222 & 257 \\
\hline 1997 & 270 & 292 & 235 & 234 & 268 & 244 & 243 & 268 \\
\hline 1998 & 243 & 356 & 305 & 295 & 324 & 301 & 298 & 323 \\
\hline 1999 & 257 & 357 & 366 & 351 & 380 & 363 & 360 & 378 \\
\hline 2000 & 274 & 342 & 352 & 337 & 377 & 351 & 346 & 376 \\
\hline 2001 & 267 & 333 & 341 & 325 & 361 & 338 & 335 & 359 \\
\hline 2002 & 258 & 323 & 334 & 318 & 356 & 333 & 329 & 352 \\
\hline 2003 & 253 & 312 & 319 & 305 & 342 & 315 & 314 & 340 \\
\hline 2004 & 249 & 313 & 315 & 299 & 329 & 313 & 311 & 328 \\
\hline 2005 & 238 & 309 & 309 & 295 & 332 & 303 & 303 & 331 \\
\hline 2006 & 226 & 322 & 313 & 295 & 329 & 310 & 310 & 328 \\
\hline 2007 & 257 & 327 & 328 & 312 & 345 & 325 & 322 & 345 \\
\hline 2008 & 296 & 294 & 310 & 292 & 346 & 304 & 299 & 346 \\
\hline Total & 3618 & 4300 & 4234 & 4589 & 4231 & 4199 & 4572 & 4058 \\
\hline
\end{tabular}

A metodologia em pooled regression envolve regressões que combinam dados em crosssection com a evolução do tempo, permitindo capturar o comportamento dos dados tanto na dimensão espacial quanto na temporal (MEDEIROS, COSTA e SILVA, 2005). Considerando-se os dados disponíveis, essa análise contou com 2519 observações ao longo do período entre 1995 e 2008.

Para mitigar problemas relacionados com eventual heterocedasticidade, os erros-padrão foram estimados por meio da matriz de covariância robusta de White.

A fim de aprofundar a observação dos resultados e de se obter maior embasamento para análise, os dados, também, foram separados por setor econômico, de modo que essa classificação pudesse ajudar a compreender os resultados agregados.

\section{ANÁLISE DOS RESULTADOS}

\subsection{Estatística descritiva e resultados iniciais}

A Tabela 2, painel A, apresenta a estatística descritiva para a amostra total das empresas englobando o período entre 1995 e 2008.
Foram calculados os coeficientes de correlação entre as variáveis e os retornos com o objetivo de medir o grau de dependência linear entre os indicadores, utilizando, ainda, o método do produto-momento de Pearson ("r de Pearson") para verificar os $p$-valores das correlações e perceber se há significância ou não na relação. No caso, foram testadas todas as variáveis contra o retorno das ações.

Também, foram realizados testes de diferença de média para as variáveis ROA e ROA operacional, no intuito de descobrir se há diferença entre as médias encontradas para cada um deles, e se elas são significantes ou não, e, assim, inferir se um deles possui maior poder explicativo sobre os retornos que outro. Os testes foram feitos tanto para os dados em pooled como para em cross-section. 
Tabela 2 Estatística descritiva das variáveis retorno, ML, GA, ROA, AL, ROA operacional, spread e AFL

\begin{tabular}{c|c|c|c|c|c|c|c|c}
\hline \multicolumn{1}{c}{ Painel A } \\
\hline Variável & Média & $\begin{array}{c}\text { Desvio- } \\
\text { Padrão }\end{array}$ & Mín. & Q1 & Mediana & Q3 & Máx. & N \\
\hline Retorno & 0,2437 & 0,7520 & $-0,7760$ & $-0,2720$ & 0,0680 & 0,5360 & 3,6970 & 3618 \\
\hline ML & $-0,0316$ & 0,2458 & $-1,8759$ & $-0,0494$ & 0,0204 & 0,0719 & 0,4048 & 4300 \\
\hline GA & 0,9990 & 0,6610 & 0,0001 & 0,5206 & 0,8956 & 1,3673 & 3,4429 & 4234 \\
\hline ROA & $-0,0020$ & 0,1268 & $-0,6338$ & $-0,0343$ & 0,0199 & 0,0672 & 0,2327 & 4589 \\
\hline AL & 2,8389 & 3,1294 & $-5,1605$ & 1,4523 & 2,0980 & 3,3110 & 22,4882 & 4231 \\
\hline ROAop & 0,0941 & 0,2722 & $-1,2500$ & 0,0068 & 0,0933 & 0,2015 & 1,2325 & 4199 \\
\hline Spread & 0,4237 & 3,8303 & $-12,3963$ & $-0,3572$ & $-0,2865$ & 0,2632 & 36,2799 & 4572 \\
\hline AFL & 0,1650 & 0,6098 & $-1,7111$ & $-0,0956$ & 0,0202 & 0,3313 & 3,3632 & 4058 \\
\hline \multicolumn{7}{c}{ Painel B - Regressões em pooled OLS: } \\
\hline
\end{tabular}
(A) $R_{i, t}=\alpha_{0}+\beta_{1} R O A_{i, t}+\beta_{2} A L_{i, t}+\ldots+\varepsilon$
(B) $R_{i, t}=\alpha_{0}+\beta_{1} M L_{i, t}+\beta_{2} G A_{i, t}+\beta_{3} A L_{i, t}+\ldots+\varepsilon$
(C) $R_{i, t}=\alpha_{0}+\beta_{1}$ ROAop $_{i, t}+\beta_{2}$ Spread $_{i, t}+\beta_{3} A F L_{i, t}+\ldots+\varepsilon$

\begin{tabular}{c|c|c}
\hline \multicolumn{3}{c}{ Variável dependente: } \\
Retorno das Ações \\
\hline & Coef. & $p$ valor \\
\hline ML $^{2}$ & 0,4021 & 0,006 \\
\hline GA $^{2}$ & 0,0960 & 0,024 \\
\hline ROA $^{1}$ & 1,2009 & 0,000 \\
\hline AL $^{2}$ & 0,0025 & 0,748 \\
\hline ROAop $^{3}$ & 0,3085 & 0,003 \\
\hline Spread $^{3}$ & 0,0029 & 0,715 \\
\hline AFL $^{3}$ & $-0,0123$ & 0,780 \\
\hline
\end{tabular}

Nota - definição das variáveis:

$\mathrm{R}$ - retorno da ação, calculado pela subtração do preço da ação ao fim do ano pelo preço ao fim do ano anterior e dividindo-se o resultado por esse último;

$\mathrm{ML}$ - margem líquida, calculada pela divisão do lucro líquido ao fim do ano pela receita bruta ao fim do ano anterior;

GA - giro do ativo, obtido pela divisão da receita bruta ao fim do ano pelo ativo total ao fim do ano anterior;

$\mathrm{AL}$ - grau de alavancagem da empresa, resultante da divisão do ativo total ao fim do ano pelo patrimônio líquido ao final do ano anterior;

ROAop - retorno sobre o ativo operacionail, calculado pela divisão do lucro operacional líquido após os impostos pelo patrimônio líquido ao final do ano anterior;

Spread - representa o efeito econômico incremental quando da introdução, pela empresa, de dívida em sua estrutura operacional. Definida pela subtração da taxa de juros efetiva após impostos do ROAop;

AFL - alavancagem financeira líquida, calculada pela divisão da dívida líquida ao final do ano anterior pelo patrimônio líquido ao final do ano anterior;

1 - Indica que o coeficiente foi calculado por meio da regressão A;

2- Indica que o coeficiente foi calculado por meio da regressão B;

3- Indica que o coeficiente foi calculado por meio da regressão C.

No painel A da Tabela 2 são apresentadas as estatísticas descritivas das variáveis financeiras avaliadas no estudo. Destaque-se que a média (mediana) do retorno sobre o ativo - ROA das empresas da amostra é de -0,002 $(0,0199)$ enquanto a média (mediana) do re- 
torno sobre o ativo operacional - ROAop. é de 0,094 (0,0933) demonstrando a relevância da avaliação mais aprofundada de qual métrica de retorno sobre os ativos está mais correlacionada com o valor da empresa. No painel B da Tabela 2, relaciona-se o retorno das ações com as diferentes decomposições do ROE (DuPont e DuPont modificada), a partir da realização de uma regressão pooled OLS, com as variáveis componentes do modelo DuPont (e DuPont modificado). Os resultados apontam para a existência de relação positiva entre ROA e ROA operacional e os retornos das ações, e essa relação se mostra estatisticamente significante. Como era esperado, em função de serem componentes do $\mathrm{ROA}$, os índices de margem líquida e giro do ativo, também, apresentam relação positiva e significante com os retornos.
Por outro lado, não se observa a mesma situação com os índices financeiros, pois embora apresentem relação positiva com os retornos, ela não é estatisticamente significante.

A seguir, os resultados são avaliados em maior detalhamento.

\subsection{Avaliação da relação dos retornos com o ROA e ROA operacional}

Aprofundando ainda mais essa análise, a Tabela 3 apresenta os coeficientes de regressão e de correlação para ROA (utilizando-se a regressão A) e ROA operacional (utilizandose a regressão C) com os retornos das ações, divididos ano a ano (cross-section) e agregados (pooled), de forma que é possível visualizar a predominância de relações positivas e significantes entre essas variáveis e o retorno das ações.

Tabela 3 Coeficientes de regressão e de correlação dos indicadores ROA e ROA operacional com retorno das ações (por ano)

\begin{tabular}{l|c|c|c|c|c|c|c|c}
\hline \multirow{2}{*}{ Ano } & \multicolumn{5}{|c}{ ROA } & \multicolumn{3}{c}{ ROAop } \\
\cline { 2 - 9 } & Coeficiente & $\boldsymbol{p}$-valor & Correlação & $\boldsymbol{p}$-valor & Coeficiente & $\boldsymbol{p}$-valor & Correlação & $\boldsymbol{p}$-valor \\
\hline 1995 & 1,0274 & 0,054 & 0,3820 & 0,000 & 0,4389 & 0,217 & 0,2370 & 0,000 \\
\hline 1996 & 1,6588 & 0,367 & 0,2945 & 0,000 & 0,7081 & 0,367 & 0,2226 & 0,000 \\
\hline 1997 & 2,2040 & 0,008 & 0,3065 & 0,000 & 0,9002 & 0,000 & 0,2809 & 0,000 \\
\hline 1998 & 1,1993 & 0,035 & 0,0053 & 0,940 & 0,2206 & 0,272 & 0,0814 & 0,230 \\
\hline 1999 & 4,2089 & 0,000 & 0,3044 & 0,000 & 0,8947 & 0,144 & 0,2924 & 0,000 \\
\hline 2000 & 0,1042 & 0,890 & 0,1972 & 0,000 & 0,1250 & 0,618 & $-0,0931$ & 0,140 \\
\hline 2001 & 2,1249 & 0,000 & 0,3623 & 0,000 & 0,6315 & 0,000 & 0,2534 & 0,000 \\
\hline 2002 & 2,3859 & 0,001 & 0,2829 & 0,000 & 0,4255 & 0,085 & 0,1623 & 0,010 \\
\hline 2003 & 1,5948 & 0,204 & 0,2384 & 0,000 & 0,1166 & 0,735 & 0,1132 & 0,090 \\
\hline 2004 & 1,7971 & 0,074 & 0,2267 & 0,000 & 0,0806 & 0,773 & 0,1923 & 0,000 \\
\hline 2005 & 2,7215 & 0,006 & 0,2272 & 0,000 & 0,3183 & 0,210 & 0,1556 & 0,020 \\
\hline 2006 & 1,1907 & 0,012 & 0,2381 & 0,000 & 0,5534 & 0,035 & 0,1096 & 0,120 \\
\hline 2007 & $-1,9151$ & 0,002 & $-0,1829$ & 0,010 & $-0,1789$ & 0,608 & 0,0065 & 0,920 \\
\hline 2008 & 0,0474 & 0,821 & 0,2120 & 0,000 & 0,0529 & 0,742 & 0,0423 & 0,530 \\
\hline Pooled & 1,2009 & 0,000 & 0,1737 & 0,000 & 0,3085 & 0,003 & 0,1501 & 0,000 \\
\hline
\end{tabular}

De acordo com o resultado da Tabela 3, à exceção dos anos de 2000 e de 2008, o grau de relacionamento entre o ROA e os retornos é maior que entre o ROA operacional e os mesmos retornos. O mesmo se observa com o grau de correlação, que só é maior para o ROA operacional nos anos de 1998 (ano em que, entretanto, ambas as correlações não são estatisticamente significantes).

Além disso, a relação entre ROA e retor- 
nos é estatisticamente significante nos anos 1997, 1999, 2001, 2002, 2005, 2006 e 2007, ao passo que, para o ROA operacional, isso só ocorre em 1997, 2001 e 2006.

Os resultados encontrados até aqui sugerem, portanto, maior influência do ROA sobre o desempenho das ações das empresas brasileiras na Bovespa.

Contudo, a fim de buscar maiores evidências que pudessem atestar se essa diferença encontrada entre ROA e ROA operacional e os retornos das ações é de fato significante, foram, ainda, realizados testes de média, tanto com a amostra em cross-sections quanto com a agregada (dados em pooled). No teste de média, têm-se:

$$
\begin{aligned}
& \mathrm{H}_{0}: \mathrm{ROA}=\text { ROAop. } \\
& \mathrm{H}_{1}: \mathrm{ROA} \neq \text { ROAop. }
\end{aligned}
$$

Os resultados são demonstrados na Tabela 4 .

\begin{tabular}{|c|c|c|c|c|}
\hline Ano & ROA op. & ROA & $\begin{array}{c}\text { Ha: diff } !=0 \operatorname{Pr}(|\mathrm{T}| \\
>|\mathrm{t}|)\end{array}$ & Teste de diferenças de média \\
\hline 1995 & $-0,0117$ & $-0,1570$ & 0,8395 & Não há diferença de médias \\
\hline 1996 & 0,0319 & $-0,0065$ & 0,0298 & Há diferença de médias \\
\hline 1997 & 0,0533 & $-0,0066$ & 0,0009 & Há diferença de médias \\
\hline 1998 & 0,0512 & $-0,0174$ & 0,0000 & Há diferença de médias \\
\hline 1999 & 0,0550 & $-0,0333$ & 0,0000 & Há diferença de médias \\
\hline 2000 & 0,0766 & $-0,0032$ & 0,0000 & Há diferença de médias \\
\hline 2001 & 0,0984 & $-0,0083$ & 0,0000 & Há diferença de médias \\
\hline 2002 & 0,1061 & $-0,0348$ & 0,0000 & Há diferença de médias \\
\hline 2003 & 0,1255 & 0,0096 & 0,0000 & Há diferença de médias \\
\hline 2004 & 0,1488 & 0,0244 & 0,0000 & Há diferença de médias \\
\hline 2005 & 0,1258 & 0,0129 & 0,0000 & Há diferença de médias \\
\hline 2006 & 0,1332 & 0,0091 & 0,0000 & Há diferença de médias \\
\hline 2007 & 0,1299 & 0,0267 & 0,0000 & Há diferença de médias \\
\hline 2008 & 0,1445 & 0,0170 & 0,0000 & Há diferença de médias \\
\hline Pooled & 0,0941 & $-0,0020$ & 0,0000 & Há diferença de médias \\
\hline
\end{tabular}

Tabela 4 Diferenças de média entre ROA e ROA operacional (por ano)

A Tabela 4, ao comparar os valores médios das duas formas de Retorno sobre o Ativo, assegura a existência de diferença entre esses valores, permitindo, assim, estabelecer comparações entre eles.

Dessa maneira, em face da comprovação da diferença estatística entre resultados de ROA e ROA operacional, há indícios de que seja possível rejeitar a hipótese nula $\mathrm{H}_{0} 1$, indicando, assim, a existência de diferença entre o poder explicativo destes fatores sobre o desempenho das ações e podendo inferir que o ROA consegue explicar melhor a geração de valor para as empresas brasileiras listadas na Bovespa.

Uma possível explicação para isso pode ser encontrada na afirmação de Palepu e Healy (2007) de que o ROA operacional mede a lucratividade com que uma empresa gera lucros operacionais a partir de seus ativos operacionais. Não são considerados, portanto, resultados advindos de ativos financeiros. Ao contrário, o ROA leva em conta tanto ativos operacionais quanto financeiros. Em tempos em que as operações no mercado financeiro pelas empresas tornam-se mais frequentes e envolvem grandes volumes de capital, podem-se obter retornos consideráveis por meio delas.

O próprio lucro líquido utilizado no cálculo do ROA envolve ganhos provenientes de decisões financeiras, o que pode, da mesma 
maneira, ter influência sobre o desempenho das empresas observadas.

\subsection{Os fatores operacionais e os financeiros}

Pretendendo comparar os indicadores operacionais com os financeiros, em termos de geração de valor para as empresas, consideraram-se os resultados das regressões A, B e C para que se pudesse identificar como se relacionam os componentes financeiros do ROE e o retorno das ações. Para tanto, foram considerados os conceitos de alavancagem, alavancagem financeira líquida e spread, decorrentes da decomposição do ROE apresentadas nas equações I, II e III apresentadas no item 3.2. Os resultados são apresentados na Tabela 5 .

Tabela5 Coeficientes de regressão dos indicadores para o retorno das ações

\begin{tabular}{c|c|c|c|c|c|c|c|c}
\hline Variável & Coeficiente & $\boldsymbol{p}$ valor & Variável & Coeficiente & $\boldsymbol{p}$ valor & Variável & Coeficiente & $\boldsymbol{p}$ valor \\
\hline $\mathrm{ML}$ & 0,4021 & 0,0060 & $\mathrm{ROA}$ & 1,2009 & 0,0000 & ROAop & 0,3085 & 0,0030 \\
\hline $\mathrm{GA}$ & 0,0960 & 0,0240 & $\mathrm{AL}$ & 0,0025 & 0,7480 & Spread & 0,0029 & 0,7150 \\
\hline $\mathrm{AL}$ & 0,0025 & 0,7480 & & & & $\mathrm{AFL}$ & $-0,0123$ & 0,7800 \\
\hline & $\mathrm{R}^{2}$ & 0,1059 & & $\mathrm{R}^{2}$ & 0,1087 & & $\mathrm{R}^{2}$ & 0,0785 \\
\hline
\end{tabular}

Verifica-se que os coeficientes de regressão dos indicadores operacionais são sensivelmente maiores que os financeiros. São encontrados resultados positivos e estatisticamente significantes para as variáveis ROA e ROA operacional, bem como para margem líquida e giro do ativo. Por outro lado, embora apresentem coeficientes positivos, os resultados dos indicadores financeiros não apresentam significância estatística.

Os resultados apresentados sugerem haver maior influência dos fatores operacionais que dos financeiros sobre o desempenho das ações das empresas brasileiras negociadas na Bovespa, indicando, portanto, a rejeição da hipótese nula $\mathrm{H}_{0} 2$. Seria, com isso, possível afirmar que existe diferença entre o poder explicativo dos indicadores componentes do ROE sobre a geração de valor das ações de empresas brasileiras na Bovespa, sendo que esse poder é maior para ROA, ROA operacional, margem líquida e giro do ativo.

Esses resultados corroboram, em parte, as conclusões de Penman, Richardson e Tuna (2007), para empresas americanas, segundo as quais o desempenho das ações das empresas estaria ligado em maior parte às estratégias e decisões de produção, marketing, logística, operações e custos, por exemplo, que puramente à política de investimentos ou estrutura de capital. Dessa maneira, a pesquisa no contexto norte-americano encontra conclusões semelhantes ao mercado brasileiro.

A diferença está na influência da alavancagem sobre os retornos que Penman, Richardson e Tuna (2007) demonstram ser uma relação negativa, enquanto esta pesquisa encontrou relação positiva, mas que, entretanto, não permite afirmar que ela seja de fato relevante.

\subsection{A alavancagem e o retorno das ações}

Modigliani e Miller (1958) encontram em sua pesquisa resultados que apontam para uma correlação positiva entre indicadores de alavancagem e o desempenho das empresas. Os resultados apresentados por esta pesquisa até aqui fornecem indícios que não sustentam relação semelhante para as empresas negociadas na Bovespa.

A Tabela 5, embora exponha uma relação positiva, mostra não haver significância estatística na relação das variáveis alavancagem, spread e alavancagem financeira líquida com os desempenhos das ações das empresas.

A Tabela 6 apresenta os dados em crosssection para o período pesquisado. 
Tabela 6 Coeficientes de regressão dos indicadores financeiros com retorno da ações (por ano)

\begin{tabular}{l|c|c|c|c|c|c}
\hline \multirow{2}{*}{ Ano } & \multicolumn{2}{|c|}{ AL } & \multicolumn{2}{c|}{ Spread } & \multicolumn{2}{c}{ AFL } \\
\cline { 2 - 7 } & Coeficiente & $p$ valor & Coeficiente & $p$ valor & Coeficiente & $p$ valor \\
\hline 1995 & $-0,0077$ & 0,664 & $-0,0155$ & 0,190 & $-0,1957$ & 0,078 \\
\hline 1996 & 0,0281 & 0,796 & $-0,0089$ & 0,477 & 0,8727 & 0,061 \\
\hline 1997 & 0,0116 & 0,719 & 0,0028 & 0,839 & 0,0889 & 0,680 \\
\hline 1998 & $-0,0129$ & 0,620 & 0,0292 & 0,276 & $-0,0758$ & 0,439 \\
\hline 1999 & $-0,0108$ & 0,691 & 0,0780 & 0,236 & 0,0347 & 0,884 \\
\hline 2000 & $-0,0209$ & 0,069 & 0,0711 & 0,036 & $-0,1136$ & 0,021 \\
\hline 2001 & $-0,0097$ & 0,447 & $-0,0273$ & 0,003 & $-0,0941$ & 0,077 \\
\hline 2002 & $-0,0210$ & 0,273 & $-0,0114$ & 0,182 & $-0,2033$ & 0,005 \\
\hline 2004 & 0,0332 & 0,060 & 0,0440 & 0,000 & 0,0913 & 0,402 \\
\hline 2005 & 0,0130 & 0,429 & 0,0309 & 0,049 & $-0,0899$ & 0,661 \\
\hline 2006 & 0,0384 & 0,153 & $-0,1151$ & 0,000 & 0,2407 & 0,034 \\
\hline 2007 & 0,0201 & 0,356 & $-0,0390$ & 0,252 & 0,2614 & 0,009 \\
\hline Pooled & 0,0345 & 0,278 & $-0,0763$ & 0,090 & 0,0970 & 0,602 \\
\hline AL: gra & 0,0048 & 0,682 & 0,0025 & 0,522 & 0,0085 & 0,867 \\
\hline
\end{tabular}

AL: grau de alavancagem da empresa, resultante da divisão do ativo total ao fim do ano anterior pelo patrimônio líquido ao final do ano anterior.

Spread: representa o efeito econômico incremental quando da introdução, pela empresa, de dívida em sua estrutura operacional. Definida pela subtração da taxa de juros efetiva após impostos do ROAop.

AFL: alavancagem financeira líquida, calculada pela divisão da dívida líquida ao final do ano anterior pelo patrimônio líquido ao final do ano anterior.

Não há significância estatística para alavancagem; para o spread, apenas em 2000, 2001, 2003, 2004 e 2005; para a alavancagem financeira líquida nos anos de 2000, 2002, 2005 e 2006.

Esses resultados, consequentemente, le- vantam indicativos que permitiriam não rejeitar $\mathrm{H}_{0} 3$, não sendo possível determinar se há ou não reflexo das decisões de financiamento sobre o desempenho das ações, em virtude de não haver significância estatística nos resultados.

\section{CONCLUSÃO}

Diversos agentes do mercado de capitais se utilizam da análise de demonstrações financeiras no intuito de medir e compreender o desempenho econômico das empresas. Com base nesses relatórios, é possível produzir índices, indicadores e previsões que possam estabelecer comparações e, assim, embasar as decisões dos participantes do mercado. Uma das mais tradicionais análises aplicadas sobre o retorno sobre o patrimônio líquido é sua decomposição em margem, giro e alavancagem (chamada de análise DuPont). Essa decomposição (análise DuPont)permite avaliar quanto do retorno dos acionistas é resultante das atividades relacionadas diretamente com as operações das empresas e quanto está relaciona- 
do com as atividades financeiras da entidade. Críticos desse modelo sugerem que a análise DuPont mistura os conceitos operacionais e financeiros, o que não gera uma visão efetivamente clara sobre o desempenho da empresa. Surge, então, uma decomposição alternativa da fórmula DuPont, chamada de análise $\mathrm{Du}$ Pont modificada, em que se separam os efeitos operacionais dos efeitos financeiros na avaliação do desempenho da empresa.

$\mathrm{O}$ presente artigo investigou quais dos modelos de decomposição do ROE, os modelos DuPont e DuPont modificado e, consequentemente, os fatores de rentabilidade a eles associados (ROA e ROA operacional, respectivamente), explica melhor o desempenho das ações de empresas brasileiras listadas na Bovespa.

Os testes empíricos apontam para maior poder explicativo por parte do ROA sobre o retorno das ações. Uma explicação para esse resultado reside no fato de que, ao incluir o resultado financeiro, considerando-se as altas taxas de juros no mercado brasileiro, o ROA operacional mensura o grau de lucratividade com que uma empresa obtém resultados operacionais a partir dos ativos de mesma linha, ou seja, sem conter os efeitos decorrentes de resultados financeiros e alavancagem em seu cálculo, conforme apontam Palepu e Healy (2007). A influência dos resultados provenientes de ativos e passivos financeiros aumentaria, assim, o poder explicativo do ROA sobre o desempenho das ações.

Os testes de média comprovam a existência de diferença estatística entre os valores apresentados pelas duas variáveis, o que sugere a rejeição de $\mathrm{H}_{0} 1 \mathrm{e}$, consequentemente, a conclusão de que o ROA possui relação mais acentuada com a geração de valor para as empresas brasileiras listadas na Bovespa do que o ROA operacional.

Nesse contexto, analistas e gestores devem considerar a análise do retorno operacional dos ativos como informação adicional ao indicador tradicional do retorno sobre os ativos
(ROA) para sua tomada de decisão. Adicionalmente, um dos objetivos específicos da pesquisa consistiu em uma comparação entre os coeficientes de cada equação, de maneira a avaliar se os fatores operacionais explicam os retornos das ações mais satisfatoriamente que os fatores financeiros.

Os resultados provenientes dos testes empíricos apontaram haver maior poder explicativo por parte dos fatores operacionais, sugerindo não ser possível aceitar $\mathrm{H}_{0} 2$. Em outras palavras, pode-se dizer que esses fatores explicam melhor a geração de valor que os financeiros.

Os resultados encontrados aqui, para as empresas brasileiras, corroboram em parte os de Penman, Richardson e Tuna (2007), para empresas americanas. Ambos indicam haver relação positiva e significante para os índices operacionais. Todavia, aqui, se viu que a correlação e os coeficientes de regressão entre índices financeiros e retornos é positiva, mas não significante, enquanto os autores encontram relação negativa no mercado norteamericano. Um objetivo adicional proposto neste trabalho foi o de examinar se há relação entre os fatores de alavancagem das empresas e o retorno de suas ações, e daí identificar se ela é positiva ou negativa. Nesse ponto, os resultados encontrados não permitem concluir haver ou não relação entre os fatores, pois, conforme descrito anteriormente, não foi encontrada significância estatística na relação, não permitindo, assim, rejeitar $\mathrm{H}_{0} 3$.

Como sugestões para pesquisas futuras, tem-se o aprofundamento no modelo $\mathrm{Du}$ Pont, investigando a relação entre a margem líquida e o giro do ativo acerca do poder explicativo sobre o ROE, podendo compreender todos os setores econômicos. O mesmo pode-se propor para o modelo alternativo, analisando a decomposição do ROA operacional em margem operacional e giro operacional ou, ainda, na mesma linha, detalhando a relação entre os indicadores financeiros (spread e alavancagem financeira líquida). 


\section{Referências}

ABARBANELL, Jeffery S.; BUSHEE, Brian J. Abnormal Returns to a Fundamental Analysis Strategy. The Accounting Review, v. 73, n. 1, p. 19-45, 1998. Fundamental analysis, future earnings, and stock prices. Journal of Accounting Research, v. 35, n. 1, p. 1-24, 1997.

CHENG, Peter; ZHANG, Guochang. How do Accounting Variables Explain Stock Prices Movements? Theory and Evidence. Journal of Accounting and Economics, v. 43, p. 219-244, 2006.

FAMA, Eugene F. Efficient Capital Markets: A Review of Theory and Empirical Work. The Journal of Finance, v.25, n. 2, p. 383-417, 1970.

; FRENCH, Keneth R. The Cross-Section of

Expected Returns. Journal of Finance, v.47, p. 427-466, 1992.

FEROZ, E. H.; KIM, S.; RAAB, R. L. Financial Statement Analysis: A Data Envelopment Analysis Approach. The Journal of the Operational Research Society, v. 54, n. 1, p. 48-58, 2003.

FIGUEIREDO, Gabriela; FAMÁ, Rubens; DA SILVEIRA; Alexandre de Miceli. Nível de Endividamento e Transparência das Empresas Brasileiras. In: SEMINÁRIOS EM ADMINISTRAÇÃO, 8., 2005, São Paulo. Anais... São Paulo: Semead, 2005.

GALDI, Fernando Caio; LIMA, Vinícius S.; ILHA, Hudson F.; SCALZER, Rodrigo S. Análise fundamentalista sob a perspectiva do analista de mercado: um estudo de caso na AES TIETÊ comparando os modelos de fluxo de caixa descontado e AEG Ohlson (1995). In: CONGRESSO USP DE CONTROLADORIA E CONTABILIDADE, 9., e CONGRESSO DE INICIAÇÃO CIENTÍFICA EM CONTABILIDADE, 6., 2009, São Paulo. Anais... São Paulo: USP, 2009.

LEV, Baruch; THIAGARAJAN, S. Ramu. Fundamental Information Analysis. Journal of Accounting Research, v. 31, n.2, p. 190-215, 1993.

LIESZ, Thomas J; MARANVILLE, Steven J. Ratio Analysis featuring the Dupont Method: an overlooked topic in the finance module of small business management and entrepreneurship courses. Small Business Institute Journal, v.1, p. 17-34, 2008.
LIESZ, Thomas J. Really modified DuPont analysis: five ways to improve return on Equity. In: SBIDA 2002 CONFERENCE, 2002. San Diego, California, 2002. MEDEIROS, Otávio B.; COSTA, Patrícia de S.; SILVA, César A.T. Testes Empíricos Sobre o Comportamento Assimétrico dos Custos nas Empresas Brasileiras. Revista de Contabilidade \& Finanças, São Paulo, n. 38, p. 47 - 56, maio/ago. 2005

MODIGLIANI, F; M. MILLER, The Cost of Capital, Corporation Finance and the Theory of Investment. American Economic Review, 48, p.261-297, 1958.

OLIVEIRA, Antonio de Alencar Costa; MATSUMOTO, Alberto S. Análise dos lucros do setor de siderurgia e metalurgia pela fórmula DuPont. 2005. Artigos de Conclusão de Curso em Ciências Contábeis. Universidade Católica de Brasília - UCB, Brasília, 2005. PALEPU, Krishna G.; HEALY, Paul M. Business Analysis and Valuation Tools. 4. ed. Cengage Learning, 2007. PENMAN, Stephen H.; ZHANG, Xiao-Jun. Modeling Sustainable Earnings and P/E Ratios with Financial Statement Analysis, Working paper. Columbia University, University of California, Berkeley. 2002. Disponível em: http://papers.ssrn.com/sol3/ papers.cfm? abstract_id = 318967. Acessado em: 15/03/09.

PENMAN, Stephen H.; RICHARDSON, Scott A.;

TUNA, Irem. The Book-to-Price Effect in Stock Returns Accounting for Leverage. Journal of Accounting Research, v. 45, n. $2,2007$.

ROSTAGNO, Luciano Martin; SOARES, Karina Talamini Cost; SOARES, Rodrigo Oliveira. O Perfil Fundamentalista das Carteiras Vencedoras e Perdedoras na Bovespa no Período de 1995 a 2002. Brazilian Business Review, v. 5,n.3, p. 271-288, 2008.

SOLIMAN, Mark T. Using Industry-Adjusted DuPont Analysis to Predict Future Profitability, Working Paper, Stanford University, 2004. Diponível em: http: //ssrn. com/abstract $=456700$. Acesso em: 13/10/08.

. The Use of DuPont Analysis by Market

Participants. The Accounting Review, v. 83, n. 3, 2008. WOOLDRIDGE, Jeffrey M. Introdução à Econometria: Uma Abordagem Moderna. São Paulo: Pioneira Thomson Learning, 2006. 